\title{
Impact of Surgery on Quality of Life of Ugandan Women With Symptomatic Pelvic Organ Prolapse: A Prospective Cohort Study
}

\author{
Musa Kayondo ( $\nabla$ kayondo78@gmail.com ) \\ Mbarara University of Science and Technology \\ Dan Kabonge Kaye \\ Makerere University College of Health Sciences \\ Richard Migisha \\ Mbarara University of Science and Technology \\ Rodgers Tugume \\ Mbarara University of Science and Technology \\ Paul Kalyebara Kato \\ Mbarara University of Science and Technology \\ Henry Mark Lugobe \\ Mbarara University of Science and Technology \\ Verena Geissbuehler \\ Kantonsspital Winterthur
}

\section{Research Article}

Keywords: Mbarara, Impact, Pelvic organ prolapse, Quality of life, Surgery

Posted Date: March 24th, 2021

DOl: https://doi.org/10.21203/rs.3.rs-343201/v1

License: (c) (i) This work is licensed under a Creative Commons Attribution 4.0 International License. Read Full License 


\section{Abstract}

Background: Pelvic Organ Prolapse (POP) is a significant public health issue that negatively affects the Quality of Life (QOL) of women in both low- and high-income countries. About $20 \%$ of women will undergo surgery for POP over their lifetime. However, there is a paucity of information on the effect of surgery on QOL especially in resource limited settings. We therefore sought to determine the QOL among women with symptomatic POP living in rural southwestern Uganda and the impact of surgery on their quality of life.

Methods: We conducted a prospective cohort study among 120 women with symptomatic POP awaiting surgery at the urogynecology unit of Mbarara Regional Referral Hospital. The QOL at baseline and at 1 year after surgery in the domains of physical performance, social interaction, emotion state, sexual life, sleep quality, personal hygiene and urinary bladder function was determined using a King's Quality of Life questionnaire. A paired t- test was used to compare the difference in mean scores at baseline and at 1year post-surgery.

Results: Of the 120 participants that were enrolled at baseline, 117(98\%) completed the follow-up at 1 year. The baseline QOL was poor. The domains with the poorest QOL were physical, social, sexual, emotional and sleep quality. The mean QOL scores in all the domains and the overall QOL significantly improved 1 year after surgery $(p<0.001)$. The overall QOL improved by $38.9 \%$ after surgery $(p<0.001)$.

Conclusion: The QOL was poor among women with symptomatic POP and surgery improved the QOL in all the domains of life. We recommend that surgery as an option for treatment of symptomatic POP should be scaled up to improve on the QOL of these women.

\section{Background}

Pelvic Organ Prolapse (POP) is defined as an anatomic support defect of the pelvic viscera resulting from the long-term failure of their supporting and suspension mechanisms (1). This weakness in the supporting mechanisms leads to descent of the pelvic organs, including the bladder, uterus, rectum and or small intestines, into or outside of the vagina (2). POP is one of the components of pelvic floor disorders (PFD) with the others being urinary incontinence, stool incontinence and obstetric fistula (1). Over the past two decades, a lot of emphasis and focus has been put on obstetric fistula as the main PFD in the developing world. POP has largely been neglected (3-5).

POP is a condition which may affect many aspects of women's life including physical, psychological, social interaction, sexual function and hygiene (6) and subsequently, the quality of life. POP is associated with a variety of urinary, bowel, sexual and psychological symptoms, which may significantly compromise the quality of life of the patients $(7,8)$. Most women with advanced stages of POP often have symptoms that cause difficulty in walking, sitting and squatting, which affects the performance of their daily household work like farming hence reducing their economic productivity $(9,10)$. In addition, women with POP frequently report limitations to their sexual life such as; lack of sexual desire, arousal, 
orgasm, and pain during intercourse which ultimately leads to loss of sexual interest with some being abandoned by their husbands $(6,8,11-13)$. Urinary incontinence is another common finding in women with high grades of POP which affects the women's quality of life (14). A number of psychological and mental health problems have been reported among women with POP including emotional disturbances, depression, loss of self-esteem, lack of sleep, rejection and isolation(15-18). Women with POP are five times more likely to have depressive symptoms than those without POP and those with depression are more likely to have a poor QOL than those without depression (19).

About $20 \%$ of women will undergo surgery for POP over their lifetime (20). The surgery is dependent on the type of prolapse and may include anterior colporrhaphy for cystocele, posterior colporrhaphy for rectocele, vaginal hysterectomy with vaginal vault suspension for uterine prolapse in those who have completed child bearing and cervicopexy for those with uterine prolapse that haven't completed child bearing (21). Conservative treatment options for pelvic organ prolapse include observation, lifestyle advice, pelvic floor muscle training and use of pessaries. Pessaries have been shown to be effective in management of symptomatic POP (22-24). However, pessaries are not readily available and hence their use among clinicians in treatment of symptomatic POP in our setting is low (25). Surgery for symptomatic POP has been shown to improve the quality of life among women with POP in high income countries by restoring the anatomy which therefore improves function $(12,26-28)$. However, there is a paucity of data from sub-Saharan Africa on the quality of life among women with POP given that women in low income countries might not have access to care for POP due to a limited number of skilled personnel to perform the surgery and lack of money for transport to treatment centers (11). There is also limited data on the impact of surgery on their quality of life.

Therefore, in this study we aimed to describe the quality of life among women with symptomatic POP in rural Southwestern Uganda before and after surgery in the seven life domains; physical, social interaction, psychological, sexual activity, personal hygiene, sleep and bladder function.

\section{Methods}

\section{Study setting and study population}

We conducted this prospective cohort study at the Urogynecology unit of Mbarara Regional Referral Hospital (MRRH) from December 1, 2018 to December 31, 2020, among women diagnosed with symptomatic pelvic organ prolapse (POP) destined for surgery. MRRH is a tertiary Hospital located in Mbarara district in Southwestern Uganda about 250 kilometers from the capital city of Kampala. MRRH is the main referral hospital of the entire southwestern Uganda serving over 10 districts and also gets patients from the neighboring countries of Tanzania, Rwanda, Burundi and the Eastern Democratic Republic of Congo (DRC).

\section{Data collection and study variables}


We conducted a cohort study among women diagnosed with symptomatic POP and were scheduled for surgery at the Urogynecology unit of Mbarara Regional Referral Hospital (MRRH) between December 1, 2018 and December 31,2020. The diagnosis, staging and decision to do surgery was made by the urogynecology surgical team. Participants were considered to have POP if they had any one of the following clinical diagnoses: cystocele, urethrocele, cystourethrocele, uterine prolapse, vault prolapse, enterocele or rectocele. Categorization and staging of POP was done using the Pelvic Organ Prolapse Quantification (POP-Q) system of 2011 into stages I, II, III and IV (29). The participants had their quality of life (QOL) determined at enrolment prior to surgery. The QOL before surgery was determined using the King's Health Questionnaire (30). This questionnaire was validated to assess the QOL among women with urinary incontinence but we used it to assess QOL among women with POP in our study as a number of women with POP have been shown to have urinary incontinence (31-33). This interviewerbased questionnaire assesses $7 \mathrm{QOL}$ domains that include physical/ daily roles performance, social interraction, sexual function, emotional/ psychological state, personal hygiene, sleep quality and bladder function. A score (\%) for each of the domains was calculated. Each life domain had a score ranging from 0 to $100 \%$. The overall QOL for each participant was obtained as an average of the total scores in the 7 domains. The higher the scores the poorer the QOL. The participants underwent surgery for the management of POP and were followed up for a period of 12 months. Participants were contacted by a phone call one week prior to their scheduled visit. The participants who could not be reached on phone were traced using the contact of their next of kin. This was to minimize loss to follow-up. Surgery was done for those who had symptomatic POP stage II, III and IV and was dependent on the type of prolapse. The different types of surgeries that were performed included anterior colporrhapy for cystocele, posterior colporrhapy for rectocele, vaginal hysterectomy with vaginal vault suspension (sacrospinous ligament or uterosacral vault suspension) for uterine prolapse in those who had completed child bearing and did not want uterine sparing surgery. Cervicopexy was done for those with uterine prolapse that hadn't completed child bearing or wanted uterine sparing surgery. The QOL at 1 year post-surgery was determined using the King's Health Questionnaire (30).

Trained research assistants who included counsellors and nurses who were not part of the surgical team conducted the interviews and completed the King's Heath Questionnaire. An interviewer guided data capture tool was administered to collect information on the baseline characteristics of the study participants. These included: age, parity, education level, marital status, occupation, smoking, alcohol use, type and severity of the prolapse. Age in years was categorized according to reproductive age groups: 1834 (early reproductive age group), 35-49 (late reproductive), 50-59 (peri-menopausal) and $\geq 60$ (postmenopausal).

\section{Power calculation}

We assumed a sample size of 120 , mean QOL score before surgery of 44.5 with a standard deviation of 20.9 and a mean QOL score after surgery of 8.0 with a standard deviation of 11.6. We therefore obtained a power of $100 \%$ to detect a difference in means. 


\section{Statistical analysis}

Data were entered into Redcap and exported to Stata 13 (StataCorp, LLP, College Station, TX, USA) for analysis. Categorical data were presented as frequencies (\%). The mean QOL score and the $95 \%$ confidence intervals for each of the seven domains and the overall mean QOL at baseline and at 1 year after surgery were calculated. The overall mean QOL score before and at 1 year after surgery was compared as well as the mean scores in each of the domains. A paired t-test was used to determine if there was a significant difference in the means. A p value of $<0.05$ was considered significant.

\section{Ethical considerations}

Ethical approvals were obtained from the Mbarara University of Science and Technology (MUST) Research Ethics Committee and the Uganda National Council for Science and Technology (UNCST) number HS368ES. We informed the participants of the study objectives and only those that gave written consent were recruited. Confidentiality was observed during all the interviews. Personal identifiers such as name and in-patient number were not collected. The study participants were assigned study ID numbers.

\section{Results}

A total of 130 women with symptomatic POP scheduled for surgery were seen during the study period. Of these, 10 declined to consent and were not included in the study. We therefore enrolled a total of 120 participants into the study. The participants were followed up to 12 months post-surgery with 117 completing the follow up period giving a completion rate of $97.5 \%$. The mean age of the study participants was 55 years $(S D \pm 15)$ with the majority $(n=46,38.3 \%)$ aged $\geq 60$ years, peasant farmers $(n=106,88.3 \%)$ and had had five or more deliveries $(n=94,78.3 \%)$ as shown in Table 1.

Majority of the participants had uterine prolapse $(n=85,70.8 \%)$ and the commonest stage of POP was stage $3(n=56,46.7 \%)$ as shown in Table 2.

The surgical procedures that were performed are shown in Table 3. The most common procedure done among the study participants was Vaginal hysterectomy with sacrospinous ligament vault fixation in 66 (55\%) of the participants.

In our study, 26 (21.7\%) participants suffered post-operative complications; these included relapse 18 (69.2\%), post-operative urethral incontinence 5 (19.2\%) and vaginal cuff sepsis $3(11.6 \%)$.

The baseline mean QOL $(95 \% \mathrm{Cl})$; overall and in the specific life domains is shown in table 4 . The participants presenting with POP had a poor QOL with a mean score at baseline of $45.5 \%(41.7 \%-$ 49.3\%). High mean QOL scores were found in the physical, social, emotional, sexual and sleep domains ranging from $40.4 \%$ to $61.9 \%$. Personal hygiene and urinary bladder function had the lowest mean QOL scores of $19.9 \%(15.1 \%-24.8 \%)$ and $13.6 \%(10.1 \%-17.2 \%)$ respectively. 
There was a significant improvement in the overall quality of life as well as in the different domains 1 year after surgery for symptomatic POP as shown in Table 3. The overall mean QOL score at baseline of $45.5 \%$ decreased by $38.9 \%$ to $6.6 \%$ at 1 year after surgery and this change was statistically significant ( $p$ $<0.001)$. There was also a decrease in all the specific QOL domains at 1 year after surgery for POP. Physical activity domain decreased by $55.1 \%$ from $66.7 \%$ to $6.6 \%$, social interaction decreased by $52.9 \%$ from $61.9 \%$ to $9 \%$, emotional status reduced by $52.8 \%$ from $58.4 \%$ to $5.6 \%$, sexual performance by $55.6 \%$ from $69.1 \%$ to $13.5 \%$ and sleep quality also decreased by $35.5 \%$ from $40.4 \%$ to $4.9 \%$. Though low at baseline, the mean scores for personal hygiene and urinary bladder function also decreased at 1 year post-surgery by $19.4 \%$ and $9 \%$ respectively. All these changes were statistically significant $(p<0.001)$.

\section{Discussion}

Our study shows that women presenting with symptomatic POP have a poor quality of life. Majority of the women had POP-Q stage III uterine prolapse. Surgical management for symptomatic POP significantly improved the QOL of these women $(p<0.001)$.

The Quality of Life among women with POP at MRRH is poor with an overall mean score of $45.5 \%$. This is similar to findings from high income countries where women with POP had a poor QOL $(34,35)$. Pelvic organ prolapse affects women's physical, social, emotional, sleep and sexual performance. Poor physical performance as was observed in other studies $(9,10,36)$ may be due to the chronic pelvic pain and pressure brought about by the prolapse stretching the pelvic ligaments making it difficult for these women to walk, bend and work. Women with POP in our study also had a poor social life score similar to what was observed in other studies $(11,36)$. This could be due to the fact that advanced stages of POP (III and IV) are associated with foul smelling vaginal discharge which limits the interaction with the community for fear of being discriminated (37). The poor QOL score among women with POP in the emotional domain was similar to what was found elsewhere $(19,36)$. Studies show that women with POP have a decreased body image, suffer shame and cannot disclose this problem to their relatives and husbands for fear of discrimination or even divorce $(11,38)$. Among the women who were still sexually active, the score in their sexual life was poor and this is similar with other studies $(6,8,11-13)$. Women with advanced POP are likely to experience dyspareunia, lack of libido and arousal ultimately leading to poor sexual performance $(8,11)$. The participants also had poor QOL score in the sleep domain similar to what has been found elsewhere (16). The poor sleep quality may be attributed to urinary and depressive symptoms $(16,19)$.

One year following surgery, the overall quality of life including physical, social, emotional, sleep and sexual performance improved. This is similar to what was observed in other studies where surgery done for the management of symptomatic POP significantly improved the women's quality of life $(6,8,12,13$, $19,36)$. Physical performance and activity improved because surgery corrects the anatomy such that there is no feeling of "something coming out of the vagina". This takes away the chronic pain and discomfort which enables the women to walk and even work comfortably (36). The social life of the women improved probably because following surgery these women no longer have a foul smell, have 
improved bladder function and absence of bulge symptoms $(36,39-41)$. The QOL in the emotional domain improved after surgery probably because women did not have any more worries about discrimination and the body image perception of women with POP has been shown to improve after surgery $(19,42)$. The sleep domain probably also improved because surgery has been shown to improve bladder symptoms such as nocturia and improved bladder emptying as well as improvement in depressive symptoms $(19,39,41,43)$. Surgery also improved the sexual life score probably because the anatomy had been corrected, women no longer had dyspareunia and also experienced an improved body perception $(11,12,42)$.

Our study has some limitations. This study was conducted at a single regional referral hospital in southwestern Uganda and the findings may not be generalizable to all other women in Uganda. The King's Health Questionnaire was validated to assess the QOL among women with urinary incontinence but we used it to assess QOL among women with POP in our study since a significant number of women with POP also have urinary incontinence.

\section{Conclusions}

Quality of life among women with POP was poor overall and surgery in the management of POP greatly improved women's quality of life. Surgery, as an option for the management of POP, should be scaled up to improve the QOL among women with symptomatic POP. In addition, women with symptomatic POP should also be offered psychosocial support and counselling because they have emotional and social problems.

\section{List Of Abbreviations}

POP: Pelvic Organ Prolapse

PFDs: Pelvic Floor Disorders

QOL: Quality of Life

POP-Q: Pelvic Organ Prolapse Quantification

MRRH: Mbarara Regional Referral Hospital

MUST: Mbarara University of Science and Technology

UNCST: Uganda National Council of Science and Technology

\section{Declarations}

Ethical approval and consent to participate: ethical approvals were obtained from the Mbarara University of science and Technology (MUST) Research Ethics committee and the Uganda National Council of 
Science and Technology (UNCST) number HS368ES. Written consent was obtained from all the study participants. All the experiment protocol for involving humans was in accordance to guidelines of national/ international/ institutional or declaration of Helsinki.

Consent to publication: Not applicable

Availability of data and materials: The datasets used and/or analyzed during the current study are available from the corresponding author on reasonable request.

Competing interests: The authors declare that they have no competing interests.

Funding: We received funding from Else Kroner Fresenius Foundation in Germany, grant number 2018_HA148, to conduct this study. The funders had no role in the study design, data collection, data analysis and interpretation.

Authors' contributions: M.K, D.K.K, R.M, R.T, P.K.K, H.M.L, and V.G did the initial study design, planning and implementation. M.K, R.M, H.M.L and V.G did the data analysis. All authors read and approved the final manuscript.

Acknowledgements: The authors are grateful to the study participants, staff in the operating theatre, anesthesia department plus obstetrics and gynecology ward of Mbarara Regional Referral Hospital for the assistance given during the study.

\section{References}

1. Haylen BT, Maher CF, Barber MD, Camargo S, Dandolu V, Digesu A, et al. An International Urogynecological Association (IUGA)/International Continence Society (ICS) joint report on the terminology for female pelvic organ prolapse (POP). International urogynecology journal. 2016;27(2):165-94.

2. Obstetricians ACo, Gynecologists. Pelvic Organ Prolapse: ACOG Practice Bulletin, Number 214. Obstetrics and gynecology. 2019;134(5):e126-e42.

3. Akter F, Gartoulla P, Oldroyd J, Islam RM. Prevalence of, and risk factors for, symptomatic pelvic organ prolapse in Rural Bangladesh: a cross-sectional survey study. International urogynecology journal. 2016;27(11):1753-9.

4. Asresie A, Admassu E, Setegn T. Determinants of pelvic organ prolapse among gynecologic patients in Bahir Dar, North West Ethiopia: a case-control study. International journal of women's health. 2016;8:713.

5. Ballard K, Ayenachew F, Wright J, Atnafu H. Prevalence of obstetric fistula and symptomatic pelvic organ prolapse in rural Ethiopia. International urogynecology journal. 2016;27(7):1063-7.

6. Vitale SG, Lagana AS, Gulino FA, Tropea A, Tarda S. Prosthetic surgery versus native tissue repair of cystocele: literature review. Updates in surgery. 2016;68(4):325-9. 
7. Barber MD, Maher C. Apical prolapse. International urogynecology journal. 2013;24(11):1815-33.

8. Caruso S, Bandiera S, Cavallaro A, Cianci S, Vitale SG, Rugolo S. Quality of life and sexual changes after double transobturator tension-free approach to treat severe cystocele. European Journal of Obstetrics \& Gynecology and Reproductive Biology. 2010;151(1):106-9.

9. Brandt C, van Vuuren ECJ. Dysfunction, activity limitations, participation restriction and contextual factors in South African women with pelvic organ prolapse. The South African Journal of Physiotherapy. 2019;75(1).

10. Digesu GA, Chaliha C, Salvatore S, Hutchings A, Khullar V. The relationship of vaginal prolapse severity tosymptoms and quality of life. BJOG: An International Journal of Obstetrics \& Gynaecology. 2005;112(7):971-6.

11. Bonetti TR, Erpelding A, Pathak LR. Listening to "felt needs": investigating genital prolapse in western Nepal. Reproductive health matters. 2004;12(23):166-75.

12. Lukacz ES, Warren LK, Richter HE, Brubaker L, Barber MD, Norton P, et al. Quality of life and sexual function 2 years after vaginal surgery for prolapse. Obstetrics and gynecology. 2016;127(6):1071.

13. Ulrich $D$, Dwyer P, Rosamilia A, Lim Y, Lee J. The effect of vaginal pelvic organ prolapse surgery on sexual function. Neurourology and urodynamics. 2015;34(4):316-21.

14. Komorowski L, Chen B. Female urinary incontinence in China: experiences and perspectives. Health care for women international. 2006;27(2):169-81.

15. Cheung RY, Lee JH, Lee L, Chung TK, Chan SS. Vaginal pessary in women with symptomatic pelvic organ prolapse. Obstetrics \& Gynecology. 2016;128(1):73-80.

16. Ghetti C, Skoczylas LC, Oliphant SS, Nikolajski C, Lowder JL. The emotional burden of pelvic organ prolapse in women seeking treatment: a qualitative study. Female pelvic medicine \& reconstructive surgery. 2015;21(6):332.

17. Gjerde JL, Rortveit G, Muleta M, Adefris M, Blystad A. Living with pelvic organ prolapse: voices of women from Amhara region, Ethiopia. International urogynecology journal. 2017;28(3):361-6.

18. Krause HG, Hall BA, Ng S-K, Natukunda H, Singasi I, Goh JT. Mental health screening in women with severe pelvic organ prolapse, chronic fourth-degree obstetric tear and genital tract fistula in western Uganda. International urogynecology journal. 2017;28(6):893-7.

19. Ghetti C, Lowder JL, Ellison R, Krohn M, Moalli P. Depressive symptoms in women seeking surgery for pelvic organ prolapse. International urogynecology journal. 2010;21(7):855-60.

20. Dieter AA, Wilkins MF, Wu JM. Epidemiological trends and future care needs for pelvic floor disorders. Current opinion in obstetrics \& gynecology. 2015;27(5):380.

21. Vimplis S, Hooper P. Assessment and management of pelvic organ prolapse. Current Obstetrics \& Gynaecology. 2005;15(6):387-93.

22. Barros CR, Machado RB, de Camargo ACM, Gollop TR. Tratamento conservador de prolapso de órgão pélvico com pessário: revisão de literatura. Revista de Medicina. 2018;97(2):154-9. 
23. Powers K, Lazarou G, Wang A, LaCombe J, Bensinger G, Greston WM, et al. Pessary use in advanced pelvic organ prolapse. International urogynecology journal. 2006;17(2):160-4.

24. Teng Wah Goh J, Thayalan K, Krause HG. An audit of vaginal support pessaries for pelvic organ prolapse in western Uganda. Australian \& New Zealand Continence Journal. 2020;26(2).

25. Abdool Z. Evaluation of vaginal pessary use by South African gynaecologists. South African Journal of Obstetrics and Gynaecology. 2011;17(3):64-7.

26. Katsara A, Wight E, Heinzelmann-Schwarz V, Kavvadias T. Long-term quality of life, satisfaction, pelvic floor symptoms and regret after colpocleisis. Archives of gynecology and obstetrics. 2016;294(5):999-1003.

27. Tyagi V, Perera M, Guerrero K, Hagen S, Pringle S. Prospective observational study of the impact of vaginal surgery (pelvic organ prolapse with or without urinary incontinence) on female sexual function. International urogynecology journal. 2018;29(6):837-45.

28. Mattsson NK, Karjalainen PK, Tolppanen A-M, Heikkinen A-M, Sintonen H, Härkki P, et al. Pelvic organ prolapse surgery and quality of life-a nationwide cohort study. American journal of obstetrics and gynecology. 2020;222(6):588. e1-. e10.

29. Persu C, Chapple C, Cauni V, Gutue S, Geavlete P. Pelvic Organ Prolapse Quantification System (POPQ)-a new era in pelvic prolapse staging. Journal of medicine and life. 2011;4(1):75.

30. Kelleher C, Cardozo L, Khullar V, Salvatore S. A new questionnaire to assess the quality of life of urinary incontinent women. BJOG: An International Journal of Obstetrics \& Gynaecology. 1997;104(12):1374-9.

31. Bai S, Jeon MJ, Kim J, Chung K, Kim S, Park K. Relationship between stress urinary incontinence and pelvic organ prolapse. International urogynecology journal. 2002;13(4):256-60.

32. Muñiz KS, Pilkinton M, Winkler HA, Shalom DF. Prevalence of stress urinary incontinence and intrinsic sphincter deficiency in patients with stage IV pelvic organ prolapse. Journal of Obstetrics and Gynaecology Research. 2020.

33. Putra I, Megadhana I, Suwiyoga K, Junizaf H, Santoso B. Prevalence of urinary incontinence in women with pelvic organ prolapse at Sanglah hospital Denpasar, Bali-Indonesia. Bali Medical Journal. 2016;5(1):125-8.

34. Chan SSC, Cheung RYK, Yiu KW, Lee LL, Pang AWL, Chung TKH. Symptoms, quality of life, and factors affecting women's treatment decisions regarding pelvic organ prolapse. International urogynecology journal. 2012;23(8):1027-33.

35. Jokhio AH, Rizvi RM, MacArthur C. Prevalence of pelvic organ prolapse in women, associated factors and impact on quality of life in rural Pakistan: population-based study. BMC women's health. 2020;20:1-7.

36. Dhital R, Otsuka K, Poudel KC, Yasuoka J, Dangal G, Jimba M. Improved quality of life after surgery for pelvic organ prolapse in Nepalese women. BMC women's health. 2013;13(1):22.

37. Shrestha A, Lakhey B, Sharma J, Singh M, Shrestha B, Singh S. Prevalence of uterine prolapse amongst gynecology OPD patients in Tribhuwan university teaching hospital in Nepal and its socio- 
cultural determinants. Res Cent Women. 2009.

38. Jelovsek JE, Barber MD. Women seeking treatment for advanced pelvic organ prolapse have decreased body image and quality of life. American journal of obstetrics and gynecology. 2006;194(5):1455-61.

39. de Boer TA, Kluivers KB, Withagen MI, Milani AL, Vierhout ME. Predictive factors for overactive bladder symptoms after pelvic organ prolapse surgery. International urogynecology journal. 2010;21(9):1143-9.

40. Gjerde JL, Rortveit G, Adefris M, Belayneh T, Blystad A. Life after pelvic organ prolapse surgery: a qualitative study in Amhara region, Ethiopia. BMC women's health. 2018;18(1):74.

41. Kim MS, Lee GH, Na ED, Jang JH, Kim HC. The association of pelvic organ prolapse severity and improvement in overactive bladder symptoms after surgery for pelvic organ prolapse. Obstetrics \& gynecology science. 2016;59(3):214-9.

42. Lowder JL, Ghetti C, Moalli P, Zyczynski H, Cash TF. Body image in women before and after reconstructive surgery for pelvic organ prolapse. International urogynecology journal. 2010;21(8):919-25.

43. Himmler M, Rakhimbayeva A, Sutherland SE, Roovers J-P, Yassouridis A, Liedl B. The impact of sacrospinous ligament fixation on pre-existing nocturia and co-existing pelvic floor dysfunction symptoms. International urogynecology journal. 2020:1-10.

\section{Tables}

\section{Table 1: Showing baseline participant characteristics}




\begin{tabular}{|c|c|c|c|}
\hline \multirow[t]{2}{*}{ Characteristic } & \multicolumn{3}{|c|}{ Total $(\mathrm{N}=120)$} \\
\hline & Description & Frequency & Percentage \\
\hline \multirow[t]{4}{*}{ Age in years } & $18-34$ & 7 & 5.8 \\
\hline & $35-49$ & 35 & 29.2 \\
\hline & $50-59$ & 32 & 26.7 \\
\hline & $\geq 60$ & 46 & 38.3 \\
\hline \multirow[t]{2}{*}{ Residence } & Rural & 115 & 95.8 \\
\hline & Urban & 5 & 4.2 \\
\hline \multirow[t]{4}{*}{ Level of education } & None & 65 & 54.2 \\
\hline & Primary & 49 & 40.8 \\
\hline & Secondary & 4 & 3.3 \\
\hline & Tertiary & 2 & 1.7 \\
\hline \multirow[t]{4}{*}{ Marital status } & Married & 59 & 49.2 \\
\hline & Separated & 12 & 10.0 \\
\hline & Single & 32 & 26.7 \\
\hline & Widowed & 17 & 14.2 \\
\hline \multirow[t]{3}{*}{ Occupation } & Peasant & 106 & 88.3 \\
\hline & Business & 9 & 6.9 \\
\hline & Others & 8 & 6.7 \\
\hline \multirow[t]{3}{*}{ Monthly income ${ }^{\square}$} & $<50 \mathrm{k}$ & 84 & 70.0 \\
\hline & $50-100 k$ & 25 & 20.8 \\
\hline & $>100 \mathrm{k}$ & 11 & 9.2 \\
\hline \multirow[t]{5}{*}{ Religion } & Catholic & 48 & 40.0 \\
\hline & Protestant & 46 & 38.3 \\
\hline & Pentecost & 22 & 18.3 \\
\hline & Adventist & 3 & 2.5 \\
\hline & Muslim & 1 & 0.8 \\
\hline \multirow[t]{2}{*}{ Parity } & $0-4$ & 26 & 21.7 \\
\hline & $\geq 5$ & 94 & 78.3 \\
\hline
\end{tabular}




\begin{tabular}{|llll|} 
History of smoking & No & 82 & 68.3 \\
\cline { 2 - 4 } Currently smoking & Yes & 38 & 31.7 \\
& No & 112 & 93.3 \\
\cline { 2 - 4 } & Yes & 8 & 6.7 \\
Alcohol consumption & No & 67 & 55.8 \\
\cline { 2 - 4 } & Yes & 53 & 44.2 \\
\hline Dincome in Ugandan shillings; 1k=1000 shillings & \\
\hline
\end{tabular}

Table 2: Types and stages of POP among the study participants

\begin{tabular}{|c|c|c|c|}
\hline \multirow[t]{2}{*}{ Characteristic } & \multicolumn{3}{|c|}{ Total $(\mathrm{N}=120)$} \\
\hline & Description & Frequency & Percentage \\
\hline \multirow[t]{2}{*}{ Anterior vaginal wall prolapse } & No & 33 & 27.5 \\
\hline & Yes & 87 & 72.5 \\
\hline \multirow[t]{2}{*}{ Posterior vaginal wall prolapse } & No & 88 & 73.3 \\
\hline & Yes & 32 & 26.7 \\
\hline \multirow[t]{2}{*}{ Uterine prolapse } & No & 35 & 29.2 \\
\hline & Yes & 85 & 70.8 \\
\hline \multirow[t]{2}{*}{ Post hysterectomy Vault prolapse } & No & 114 & 95.0 \\
\hline & Yes & 6 & 5.0 \\
\hline \multirow[t]{2}{*}{ Enterocele } & No & 113 & 94.2 \\
\hline & Yes & 7 & 5.8 \\
\hline \multirow[t]{4}{*}{ POPQ stage } & 1 & 0 & 0.0 \\
\hline & 2 & 28 & 23.3 \\
\hline & 3 & 56 & 46.7 \\
\hline & 4 & 36 & 30.0 \\
\hline
\end{tabular}

Table 3: Showing surgical procedures performed among the study participants 
Vaginal hysterectomy with sacrospinous ligament vault fixation

Vaginal hysterectomy plus anterior and posterior repair with uterosacral ligament vault fixation

Posterior colporrhaphy only

Anterior colporrhaphy only

Sacrospinous vault fixation for vaginal vault prolapse

Anterior and Posterior Colporrhaphy combined

Table 4: Baseline mean QOL scores compared to mean QOL scores at 1 year after surgery for POP

\begin{tabular}{|llll|}
\hline Quality of life domains & Baseline & \multicolumn{2}{l|}{ one-year post-surgery } \\
\cline { 2 - 4 } & Mean \%(95\%Cl) & Mean\% (95\%Cl) & Pvalue \\
\hline Overall & $45.5(41.7-49.3)$ & $6.6(4.5-8.8)$ & $<0.001$ \\
\hline Physical & $66.7(60.0-73.3)$ & $11.6(8.1-15.2)$ & $<0.001$ \\
\hline Social & $61.9(55.6-68.1)$ & $9.0(5.9-12.1)$ & $<0.001$ \\
\hline Emotional & $58.4(52.3-64.6)$ & $5.6(2.6-8.5)$ & $<0.001$ \\
\hline Sexual* & $69.1(61.0-77.3)$ & $13.5(8.2-18.9)$ & $<0.001$ \\
\hline Sleep & $40.4(34.6-46.2)$ & $4.9(1.7-8.1)$ & $<0.001$ \\
\hline Hygiene & $19.9(15.1-24.8)$ & $0.5(0.3-1.7)$ & $<0.001$ \\
\hline Bladder function & $13.6(10.1-17.2)$ & $4.6(2.7-6.5)$ & $<0.001$ \\
\hline
\end{tabular}

